\title{
Technical Efficiency and Technological Gaps in Agricultural Production in Selected African Countries: A Stochastic Metafrontier Approach
}

\author{
${ }^{1}$ Aminu F.O., ${ }^{2}$ Ayinde I.A. and ${ }^{2}$ Sanusi R.A. \\ ${ }^{I}$ Department of Agricultural Technology, School of Technology, Yaba College of Technology, Epe \\ Campus, P. M. B. 2011, Yaba, Lagos State, Nigeria \\ ${ }^{2}$ Department of Agricultural Economics and Farm Management, Federal University of Agriculture, \\ Abeokuta, Nigeria
}

\author{
Received: 12 Feb. 2020/ Accepted 10 April 2020 / Publication date: 30 April 2020
}

\begin{abstract}
The study applied stochastic metafrontier model to estimate technical efficiency (TE) and technology gap ratios (TGR) in agricultural production of selected African countries. Secondary data on Agricultural production indices of four Africa countries (Nigeria, Benin, Ghana and Cameroon) over a period of 54 years (1961-2014) sourced from Food and Agricultural Organization (FAOSTAT) database was used for the study. The results of the analysis showed that, the technical efficiency scores from the region ranged from 0.822 to 0.986 with a weighted average of about $85 \%$, indicating that the agricultural production in Africa produces 85 percent of the potential output given the technology available in each country. Also, the technological gap faced by the agriculture sector in the selected countries when their performances were compared with the regional level was estimated to be 0.774 , which implies that, on the average, the selected Africa countries will have to close a gap of about $22.6 \%$ in order for them to be technically efficient. Benin recorded the lowest productivity potential ratio, while Ghana had the highest. In terms of technical efficiency relative to the meta frontier, Nigeria is the most technical efficient country while Benin appears as the least performing region. Considering the importance of agricultural production to these countries and the region as a whole, there is a need for appropriate policies directed towards the provision of technology related services that would enhance efficiency.
\end{abstract}

Keywords: agricultural production; technical efficiency, technology gap, stochastic metafrontier.

\section{Introduction}

Agriculture has been recognized over the years to play an important role in economic development of developing countries. The centrality of agriculture to the development of least developed countries or developing economies is beyond dispute. In Africa, agriculture has consistently played a dominant role in the provision of food, raw material for industries, employment for the majority, and foreign earnings, which are used in financing development activities (Hayami and Ruttan, 1971; Nkamleu et al., 2010). Agriculture production in Africa countries is also plagued with low productivity compared to non-agricultural production in the same countries or to agricultural production in developed countries. The reasons for the low agricultural productivity often include limited knowledge about methods to enhance productivity and highly productive technologies, shortage or lack of access to highly productive varieties and productivity-enhancing inputs, limited availability of liquidity and limited access to credit, and/or reluctance to invest in productivityenhancing measures due to production risk, poor product prices, and unreliable market access combined with risk aversion of poor farmers (Henningsen et al., 2015). The agriculture sector is central to achieving food security and broad-based economic growth, representing approximately $35 \%$ of the region's GDP and $60 \%$ of the active labour force. Globally, agriculture's share in GDP is only $3.2 \%$. Agricultural exports generate around USD 6 billion, or $16.3 \%$ of all products and services exported from the sub-region. Nevertheless, the sector remains constrained by low productivity and major environmental challenges. A $25 \%$ decline in rainfall over the last 50 years has had serious consequences for dryland areas. Per-hectare yields for most crops are among the lowest in the world,

Corresponding Author: Aminu F.O., Department of Agricultural Technology, School of Technology, Yaba College of Technology, Epe Campus, P. M. B. 2011, Yaba, Lagos State, Nigeria.

E-mail: folaafe02@gmail.com 
only increasing by an average of $42 \%$ between 1980 and 2005, and accounting for just $30 \%$ of the increase in agricultural and food production (Blanke, 2017)

Although Africa is endowed with ample water resources, including rivers and river basins, access to water remains a challenge. Agriculture remains predominantly rain fed and dominated by small farmers with poor access to agricultural technologies, information and financial services. As a result, African agriculture is particularly vulnerable to weather variability, soil fertility degradation, and infestations of pests and diseases. These factors have led to inefficiency in agricultural production in the region (Blanke, 2017)

\section{Statement of Research Problem}

Long-term economic development is brought about by sustainable economic growth, which is also pre-disposed by agricultural development. Agricultural development crucially depends on an efficient and most productive use of scarce production resources. Agricultural production is plagued with the scarcity of resources and hence resource use efficiency is critical to improved agricultural practices. The efficiency of a farm/firm refers to its success in producing as large amount of output as possible given a set of inputs. To determine the efficiency of a particular firm, there is need for efficiency measurement through the production of factor inputs and processes (O'Donnell et al., 2008).

The most common approaches to estimating efficiency assumes that all production units are similar and have access to the same production technology (Chen and Song, 2008). Under this assumption, a single frontier is usually estimated for purposes of evaluating the efficiency of all production units under analysis. However, there are many empirical contexts where the production units in the sample operate in slightly different production environments, which to say they have access to slightly different production possibilities sets. Such technological heterogeneity reflects differences in the social, physical and economic characteristics (e.g., geography, quality of the workforce, type of machinery) of the environments in which production takes place (O'Donnell et al., 2008). If the production units under analysis, make choices from different production possibilities sets then the common approach of estimating a single technology frontier will yield efficiency and productivity estimates that do not accurately measure the capacity of production units to transform inputs into outputs.

The recently developed meta-frontier approach of Battese and Rao (2002), Battese et al., (2004) and O'Donnell et al., (2008) allows researchers to evaluate and compare the efficiency of production units that have access to different production possibilities sets. This framework has been used extensively in the literature to evaluate the efficiency of groups of firms in industries as wide-ranging as education (e.g., McMillan and Chan (2004), Worthington and Lee (2005)), finance (e.g., Kontolaimou and Tsekouras (2010)) and agriculture (e.g., Chen and Song (2008); O'Donnell et al., (2008); Villano et al., (2010); Otieno et al., (2014); Henningsen et al., (2015); Chebil et al., (2016)). The methodology involves estimating different frontiers for different groups of production units, then measuring the distances between these so-called group frontiers and a meta-frontier. Using the meta frontier approach has been found to be more effective in comparing relative technical efficiency levels across regions and assess the potential to increase efficiency by regions (Battese et al., 2004). In fact, the advantage of meta frontier is theoretically attractive because it is based on the simple hypothesis that all producers in different regions have potential access to the same technology (O'Donnell et al., 2008). It is in the light of the above that this study seeks to compare the technical efficiency and relative technology gaps across the selected African countries.

\section{Theoretical Framework}

\section{Meta Frontier Analysis}

A meta-frontier is a useful concept when the aim of the analysis is to compare the efficiency of different groups (e.g., region, countries, plant varieties) when there is the suspicion that each group operate under different technologies and therefore their productive frontiers are different. The metaproduction function was first introduced by Hayami (1969) and Hayami and Ruttan $(1970,1971)$. The meta production function can be regarded as the envelope of commonly conceived neoclassical production functions. The methodology involves estimating different frontiers for different groups of 
production units, then measuring the distances between these so-called group frontiers and a metafrontier. The meta-frontier is a type of global frontier that envelops all the group frontiers. Rather than assessing the efficiency of individual production units with respect to the meta-frontier, the efficiency of a production unit is assessed relative to its own group frontier, and then the production environment faced by the group is assessed by measuring the distance between the group frontier and the metafrontier. The distances between different group frontiers and the meta-frontier are known as technology gap ratios (TGRs) or meta-technology ratios (MTRs). MTRs measure the potential improvements in group performance that are possible when production units are given access to the production technologies of other groups.

\section{Stochastic Meta-Frontier Function}

Hayami (1969) and Hayami and Ruttan $(1970,1971)$ introduced the concept of metaproduction function, defined as an envelope of traditional production functions, assuming that all producers of different groups (countries, regions, plant varieties, etc.) potentially have access to the same technology. Following this approach, Mundlak and Hellinghausen (1982) and Lau and Yotopoulos (1989) used the MF approach to compare aggregate agricultural productivity between countries. Battese and Rao (2002), Battese et al., (2004) consider the fact that technology could differ across regions and develop the Stochastic Meta-Frontier Function (SMF) approach. This involves a Meta-Frontier estimation, which represents the envelope of all SPF for all groups or regions. The limits for groups can be differences in country geography, regional production environment or economic development of each area or region.

\section{Stochastic Meta-Frontier Framework}

Suppose that separate stochastic production frontier (SPF) models are defined for specific groups of firms in a given industry. Assume there are $\mathrm{k}$ groups or production systems in the industry. The stochastic production frontier is specified as:

$Q_{n}=\mathrm{f}(\mathrm{x}, \beta)+\varepsilon *$

where $Q n$ is the output of the $n$th farm, $X$ is the vector of inputs used by the nth farm, $\beta$ is a vector of production parameters to be estimated $\varepsilon^{*}$ is the composite disturbance term given by: $\varepsilon^{*}=v-u$ (2)

Where $\mathrm{v}$ represents statistical noise assumed to be independently and identically distributed (IID) as a normal random variable with zero mean and variance given by $\sigma_{v}^{2}$, i.e.,

$\mathrm{v} \sim N\left(0, \sigma_{v}^{2}\right)$ (Aigner et al, 1977). Farm-specific technical inefficiency in production is typically assumed to be captured by $\mathrm{u}$, which is a non-negative random variable. The $\mathrm{u}$ is assumed to be IID half-normal, i.e., $\mathrm{u} \sim . N\left(0, \sigma_{v}^{2}\right)$ Although $\mathrm{u}$ can also assume exponential or other distributions, the half-normal distribution is preferred for parsimony because it entails less computational complexity (Coelli et al, 2005). The $\mathrm{u}$ is independent of the $\mathrm{v}$-term and it measures the TE relative to the stochastic frontier. When data are in logarithm terms, $u$ is a measure of the percentage by which a particular observation or farm fails to achieve the frontier ideal production rate (Greene, 2003). Following Battese and Corra (1977), the variation of output from the frontier due to technical inefficiency is defined by a parameter $(\gamma)$ given by:

$\gamma=\frac{\sigma_{u}^{2}}{\sigma^{2}}$ Such that $0 \leq \gamma \leq$

Where $\sigma^{2}=\sigma_{u}^{2}+\sigma_{v}^{2}$

Taking account of various determinants of TE, the stochastic frontier production function in (1), for each production system can be specified as (O' Donnell et al, 2008):

$Q_{n k}=f\left(X_{n k}, \beta_{k}\right) \exp \left(v_{n k}-Z_{n k} \delta\right)$

Where Qnk denotes the output for the $\mathrm{n}^{\text {th }}$ farm in the $\mathrm{k}^{\text {th }}$ production system; $\mathrm{f}($.$) is the functional form$ used, for example the Cobb-Douglas or translog specification; $\beta_{\mathrm{k}}$ is a vector of input parameters to be estimated for the $\mathrm{k}^{\text {th }}$ production system; $\mathrm{Z}$ is a vector of factors that influence the technical inefficiency of farms, while $\delta$ is a vector of inefficiency parameters to be estimated. The TE can be measured as the ratio of actual output observed (Equation 4) to that expected maximum level from the use of available inputs (assuming any deviation is pure noise) (Boshrabadi et al. 2008):

$T E_{n k}=\frac{f\left(X_{n k}, \beta_{k}\right) \exp \left(v_{n k}-Z_{n k} \delta\right)}{f\left(X_{n k}, \beta_{k}\right) \exp \left(v_{n k}\right)}=-Z_{n k} \delta$ 
Each frontier measures individual farmers' performance relative to the dominant technology in a particular production system. However, the model in (5) is inappropriate for comparing the performance of farms across different groups of farms that are not identical technology-wise (O’Donnell et al, 2008).

After the estimation of the individual SPF's it is necessary to verify if the various groups share the same technology. This can be done with a likelihood ratio test (LR). The LR statistic is given by

$\lambda=2 x\left\lfloor L\left(H_{A}\right)-L\left(H_{O}\right)\right\rfloor$

where $\mathrm{L}(\mathrm{H} 0)$ is the value of the log likelihood function for a stochastic frontier estimated by pooling the data for all groups and L(HA) is the sum of the values of the log-likelihood functions from the individual SPF's. The degrees of freedom for the Chi square statistic are the difference between the number of parameters estimated under $\mathrm{HA}$ and $\mathrm{HO}$. If the null hypothesis that the stochastic frontier for the pooled data is rejected in favour of the individual frontiers (HA), then the data should not be pooled and in such case the MF is the appropriate framework to estimate and compare TE across groups or regions (Battese et al., 2004)

In order to capture variations in technology within and between production systems, Battese and Rao (2002) and Battese et al., (2004) suggest the use of a meta-frontier production function to measure efficiency and technology gaps of firms producing in different technological environments. The meta-frontier is considered as a smooth function that envelopes the explained (deterministic) components of the group stochastic frontier functions (e.g., for different production systems). It explains deviations between observed outputs and the maximum possible explained output levels in the group frontiers. The meta-frontier equation can be expressed as:

$Q^{*}=f\left(X_{n}, \beta^{*}\right) n=1,2, \ldots . N$

Where $f($.$) is a specified functional form; Q^{*}$ is the meta-frontier output; and $\beta^{*}$ denotes the vector of meta-frontier parameters satisfying the constraints:

$f\left(X_{n}, \beta^{*}\right) \geq f\left(X_{n}, \beta_{k}\right)$, for all $k=1,2, \ldots k$

In order to satisfy the condition in (8), an optimization problem is solved where the sum of absolute deviations (or squared deviations) of the meta-frontier values from the values of the group frontiers are minimized:

$\min \sum_{n=1}^{N}\left|\ln f\left(X_{n}, \beta^{*}\right)-\ln f\left(X_{n}, \beta_{k}\right)\right|$

$$
\text { s.t. } \ln f\left(X_{n}, \beta^{*}\right) \geq \ln f\left(X_{n}, \beta_{k}\right)
$$

In terms of the meta-frontier, the observed output for the $\mathrm{n}^{\text {th }}$ farm in the $\mathrm{k}^{\text {th }}$ production system (measured by the stochastic frontier in (10) can be expressed as:

$Q_{n k}^{*}=\exp \left(-Z_{n k} \delta\right) * \frac{f\left(X_{n}, \beta_{k}\right)}{f X_{n}, \beta^{*}} * f\left(X_{n}, \beta^{*}\right) \exp \left(v_{n k}\right)$

Where (recall from (11) that, $-\mathrm{Znk} \delta=\mathrm{TE}_{\mathrm{nk}}$ ) the middle term in (10) represents the technology gap ratio (TGR):

$T G R_{n}=\frac{f\left(X_{n}, \beta_{k}\right)}{f\left(X_{n}, \beta^{*}\right)}$

The TGR measures the ratio of the output for the frontier production function for the $\mathrm{k}^{\text {th }}$ group or production system relative to the potential output defined by the meta frontier, given the observed inputs (Battese and Rao, 2002; Battese et al, 2004). Values of TGR closer to 1 imply that a farm in a given production system is producing nearer to the maximum potential output given the technology available for the whole industry. The TGR is subsequently referred to as meta-technology ratio (MTR) to account for the wider environment in which production takes place and other factors that might influence the potential productivity gains from a given technology. The TE of the $\mathrm{n}^{\text {th }}$ farmer relative to the meta-frontier $\left(T E_{n}^{*}\right)$ is the ratio of the observed output for the nth farm relative to the meta-frontier output:

$\mathrm{TE}_{\mathrm{n}}^{*}=\frac{\mathrm{Q}_{\mathrm{nk}}}{\mathrm{f}\left(\mathrm{X}_{\mathrm{n}}, \mathrm{\beta}^{*}\right) \exp \left(\mathrm{v}_{\mathrm{nk}}\right)}$

Following (5), (10), and (11), TE*n can be expressed as the product of the TE relative to the stochastic frontier of a given production system and the MTR:

$T E_{n}^{*}=T E_{n k} \cdot M T R_{n}$ 


\section{Methodology}

\section{Data Source}

This study is based on secondary data sourced from Food and Agricultural Organization (FAOSTAT). Data on Agricultural production indices of four Africa countries

(Nigeria, Benin, Ghana and Cameroon) over a period of 54 years (1961-2014) were randomly selected for this study. The variables considered in the models were Gross Agricultural Production ('000 \$) as output while the inputs considered include: Land [agricultural] ('000 Ha); Labour [economically active persons in agriculture] ('000); Livestock (Animal Units (Hayami and Ruttan, 1985); Tractors (No); Fertilizer[NPK] (metric tonnes) and Feed (metric tonnes)

The empirical application has four steps. First is the estimation of one SPF for each region. The second step involved the estimation of one SPF for the whole data set (pooled). The third involved the comparison of the individual SPF's with the pooled frontier to test whether the technology differs between regions (LR test). In the finally step, the calculation of the MF using the estimates from individual SPF's was performed.

\section{Analytical Techniques}

First, the parameters of the stochastic frontiers for the four countries were estimated using the translog (TL) specification

$Y_{1}=\alpha_{0}+\Sigma_{k=1}^{4} \beta_{k}^{j} x_{k l}+\frac{1}{2} \Sigma_{k i=1}^{4} \beta_{k l}^{j} x_{k l}+\beta^{j} z_{d}+v_{i}^{j}-u_{i}^{j}$

Indices $j$ and $i$ represent the input $j$ used by farmer $I$, respectively and all variables are in natural logarithms.

Six inputs were included in the model. Most of these variables have been commonly used in estimating agricultural production frontiers for developing countries (Bravo-Ureta and Pinheiro 1997; Nyemeck et al. 2008). ' $\mathrm{X}_{1}$ ' denotes the total productive land area in hectares. ' $\mathrm{X}_{2}$ ' stands for the amount of labour, which includes economically active persons in agriculture measured in ' 000 ; ' $X_{3}$ ' represents Livestock measured as the number of heads; ' $\mathrm{X}_{4}$ ' is tractors (No); ' $\mathrm{X}_{5}$ ' stands for fertilizer[NPK] measured in metric tonnes and ' $\mathrm{X}_{6}$ 'represents feed in metric tonnes. $\mathrm{V}$ 's are assumed to be independently and identically distributed $N\left(0, \sigma^{2}\right)$ two-sided random errors, independently of the U's.

Finally, the results from the TL specifications are used to estimate the MF parameters by solving the LP problem of Eq. 9.

\section{Results and Discussion}

This section describes the results of the estimation of the countries production frontiers and associated TE measures. First, the SPF results and specification tests are analyzed for regions and for the pooled data. Second, TE measures are discussed for the four countries and then the TE and MTR measures with respect to the MF are examined.

\section{Summary Statistics of the Variables for Agricultural Production}

Differences in economic development could be responsible for differences in information transmission, technology adoption and even institutions associated with agricultural production. In other words, the technology diffusion may follow a geographic connecting pattern (Chen and Song, 2008). The variation in the economic development of African countries is the motivation for estimating the differences in their agricultural technologies, that is, whether they have access to different production possibility sets which should be considered when measuring production efficiencies

The summary statistics in Table 1 display the mean cumulative variables identified in each country over the specified period. Nigeria had the highest mean amount for all the variables over the specified period. Among the other three countries, Ghana earned more in terms of their Gross Agricultural Production value and use more of agricultural land area, labour, tractor and feed as compared to Benin and Cameroon. Cameroon had the highest usage of livestock and fertilizer inputs 
when compared with Benin and Ghana. Benin recorded the least mean average of all the variables over the specified period.

From the pooled data, an average African country has 10,070 hectares of agricultural land area and employs around 6,000 agricultural labour, uses around 4,000 tractors, applies 66,000 metric tons of chemical fertilizer, while possesses around 8,000 heads of livestock and feeds them with 3 million metric tons of feed; for the analysis period (1961-2014). This generates $\$ 6.5$ million worth of agricultural product in the specified period. This reflects the peasant nature of agricultural production in the study area.

All the four countries have not really adopted the use of technology in their agricultural production as they all cannot guarantee the usage of 1 tractor per $1000 \mathrm{Ha}$ of agricultural land.

Table 1: Summary Statistics of the Variables for Agricultural Production

\begin{tabular}{|c|c|c|c|c|c|}
\hline Variables & Nigeria & Benin & Ghana & Cameroon & Pooled \\
\hline Gross Agric Prod (Y) & $\begin{array}{r}19111075.35 \\
(1440257.13)\end{array}$ & $\begin{array}{l}1075077.20 \\
(93803.77)\end{array}$ & $\begin{array}{l}3239606.28 \\
(262705.51)\end{array}$ & $\begin{array}{l}2526694.35 \\
(183012.15)\end{array}$ & $\begin{array}{l}6488113.30 \\
(620158.44)\end{array}$ \\
\hline Land $\left(\mathrm{X}_{1}\right)$ & $\begin{array}{l}30728.93 \\
(1468.09)\end{array}$ & $\begin{array}{l}1593.76 \\
(101.51)\end{array}$ & $\begin{array}{l}4331.46 \\
(187.90)\end{array}$ & $\begin{array}{l}3629.72 \\
(142.90)\end{array}$ & $\begin{array}{l}10010070.97 \\
(896.23)\end{array}$ \\
\hline Labour $\left(\mathbf{X}_{2}\right)$ & $\begin{array}{l}15325.44 \\
(446.40)\end{array}$ & $\begin{array}{l}1153.56 \\
(50.79)\end{array}$ & $\begin{array}{l}3651.52 \\
(196.78)\end{array}$ & $\begin{array}{l}2953.59 \\
(76.77)\end{array}$ & $\begin{array}{l}5771.03 \\
(400.76)\end{array}$ \\
\hline Livestock $\left(\mathbf{X}_{3}\right)$ & $\begin{array}{l}21759.26 \\
(1220.62)\end{array}$ & $\begin{array}{l}1604.22 \\
(89.36)\end{array}$ & $\begin{array}{l}2074.43 \\
(103.61)\end{array}$ & $\begin{array}{l}5321.91 \\
(269.72)\end{array}$ & $\begin{array}{l}7689.95 \\
(643.34)\end{array}$ \\
\hline Tractor $\left(\mathrm{X}_{4}\right)$ & $\begin{array}{l}12973.17 \\
(1190.26)\end{array}$ & $\begin{array}{l}141.43 \\
(7.03)\end{array}$ & $\begin{array}{l}2203.20 \\
(26.38)\end{array}$ & $\begin{array}{l}404.94 \\
(26.23)\end{array}$ & $\begin{array}{l}3930.69 \\
(465.93)\end{array}$ \\
\hline Fertilizer $\left(\mathrm{X}_{5}\right)$ & $\begin{array}{l}200940.74 \\
(22132.35)\end{array}$ & $\begin{array}{l}7044.91 \\
(715.57)\end{array}$ & $\begin{array}{l}26124.54 \\
(4524.39)\end{array}$ & $\begin{array}{l}30161.11 \\
(1962.91)\end{array}$ & $\begin{array}{l}66067.82 \\
(7763.74)\end{array}$ \\
\hline Feed $\left(X_{6}\right)$ & $\begin{array}{l}98433956.11 \\
(897035.09 .)\end{array}$ & $\begin{array}{l}329927.41 \\
(46260.54)\end{array}$ & $\begin{array}{l}873770.91 \\
(115017.68)\end{array}$ & $\begin{array}{l}481749.41 \\
(63241.27)\end{array}$ & $\begin{array}{l}2882350.96 \\
(355024.49)\end{array}$ \\
\hline
\end{tabular}

Figures in parentheses are the standard errors

\section{Production Frontiers Estimates by Region and for the Pooled Data}

The single-stage maximum likelihood procedure of the FRONTIER 4.1 program (Coelli 1996) was used to estimate the parameters of the stochastic frontiers (maximum attainable output) for each country (Table 2) and for pooled data (Table 4).

The study revealed that the gamma estimate which measures the deviation of the observed output from the frontier output is estimated to be $0.98,0.79,0.89,0.84$ and 0.69 for Nigeria, Benin, Ghana, Cameroon and the pooled data, respectively. This implies that in all the models, most of the deviations in the total output are largely as a result of the inefficiency in input use and other farm practices, whilst the random factors which may include unfavourable weather conditions, pest and disease infestation, statistical errors in data measurement and the model specification contribute $2 \%$, $21 \%, 11 \%, 16 \%$ and $31 \%$, respectively to the deviations of the actual output from the frontier output.

The study revealed that land area $(p<0.05)$, livestock $(p<0.05)$ and feed $(p<0.01)$ had positive influence on agricultural output in Nigeria. This implies that an increase in the usage of these inputs will increase agricultural output in Nigeria, ceteris paribus.

In Benin, the study revealed that livestock $(p<0.05)$, tractor $(\mathrm{p}<0.10)$, fertilizer $(\mathrm{p}<0.01)$ and feed (0.10) had positive influence on agricultural output. This indicates that a $1 \%$ increase in the usage of these inputs will increase agricultural output by $24.6 \%, 50.4 \%, 83.5 \%$ and $9.8 \%$ respectively.

Labour $(\mathrm{p}<0.01)$ and livestock $(\mathrm{p}<0.01)$ had positive influence while land $(\mathrm{p}<0.05)$ and fertilizer $(p<0.01)$ had negative influence on agricultural production in Ghana. This is similar to Li \& Wahl (2004); Djokoto (2012) who obtained a negative sign for land in Chinese and Ghana Agriculture respectively. They reported that the negative sign suggested over use of land. Thus, a decrease in land use will stimulate output ceteris paribus.

The study also revealed that land $(p<0.01)$, fertilizer $(p<0.01)$ and feed $(p<0.10)$ will increase agricultural output in Cameroon while tractor $(\mathrm{p}<0.10)$ will reduce agricultural output by $23.3 \%$. the negative effect of tractor could be due to lack of technical know-how in the operation and maintenance of the mechanical device. 
Middle East J. Agric. Res., 9(2): 282-293, 2020

Table 2: Parameter Estimates of the Stochastic Frontier Model by Country

\begin{tabular}{|c|c|c|c|c|c|c|c|c|c|}
\hline & \multirow[t]{2}{*}{ 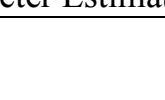 } & \multicolumn{2}{|c|}{ Nigeria } & \multicolumn{2}{|l|}{ Benin } & \multicolumn{2}{|c|}{ Ghana } & \multicolumn{2}{|c|}{ Cameroon } \\
\hline & & Coef. & S.E. & Coef. & S.E. & Coef. & S.E. & Coef. & S.E. \\
\hline & Constant & $10.483 * * *$ & 0.994 & $10.052 * * *$ & 1.134 & $9.788 * * *$ & 1.017 & $-5.224 * * *$ & 0.972 \\
\hline Land & Lnx1 & $1.645 * *$ & 0.737 & -0.431 & 0.618 & $-3.702 * *$ & 1.773 & $2.813 * * *$ & 0.453 \\
\hline Labour & $\operatorname{Ln} x 2$ & -0.215 & 0.862 & -0.450 & 0.856 & $1.948 * * *$ & 0.530 & -0.321 & 0.257 \\
\hline Livestock & $\operatorname{Ln} x 3$ & $0.649 * *$ & 0.252 & $0.246^{* *}$ & 0.091 & $0.634 * * *$ & 0.216 & 0.040 & 0.071 \\
\hline Tractor & $\operatorname{Lnx} 4$ & -0.515 & 0.354 & $0.504^{*}$ & 0.309 & -0.295 & 0.306 & $-2.327 *$ & 0.166 \\
\hline Fertilizer & $\operatorname{Lnx} 5$ & 0.064 & 0.257 & $0.835 * * *$ & 0.277 & $-0.328 * * *$ & 0.121 & $0.879 * * *$ & 0.282 \\
\hline Feed & Lnx6 & $0.095 * * *$ & 0.108 & $0.098 *$ & 0.057 & -0.062 & 0.045 & $0.102 *$ & 0.063 \\
\hline Land square & $(\ln x 1) 2$ & $0.086^{* *}$ & 0.035 & 0.053 & 0.043 & $0.266^{* *}$ & 0.114 & $-0.156 * * *$ & 0.028 \\
\hline Labour square & $(\ln \times 2) 2$ & 0.017 & 0.059 & 0.061 & 0.090 & $-0.077 * *$ & 0.033 & 0.035 & 0.029 \\
\hline Livestock square( & $(\ln x 3) 2$ & $-0.027 * * *$ & 0.008 & 0.009 & 0.011 & -0.009 & 0.001 & $0.053 * * *$ & 0.015 \\
\hline Tractor square & $(\ln x 4) 2$ & 0.006 & 0.026 & $0.174 * *$ & 0.066 & 0.007 & 0.028 & $0.040 * * *$ & 0.017 \\
\hline Fert.square & $(\ln \times 5) 2$ & 0.005 & 0.008 & $-0.059 * *$ & 0.022 & 0.010 & 0.007 & $-0.509 * *$ & 0.009 \\
\hline Feed square & $(\ln x 6) 2$ & 0.002 & 0.028 & 0.006 & 0.008 & $0.015 * * *$ & 0.004 & $-0.020 * *$ & 0.001 \\
\hline Land*lab & $\operatorname{Inx} 1 * \ln x 2$ & 0.020 & 0.035 & -0.003 & 0.024 & 0.023 & 0.065 & $-0.029 * * *$ & 0.014 \\
\hline Land*livestock & $\ln x 1 * \ln x 3$ & $0.023 * * *$ & 0.006 & $-0.083 * *$ & 0.034 & 0.005 & 0.008 & $-0.030 * *$ & 0.008 \\
\hline Land*tractor & $\ln x 1 * \ln x 4$ & 0.169 & 0.051 & 0.003 & 0.005 & 0.002 & 0.005 & $0.018 * *$ & 0.006 \\
\hline Land*fertilizer & $\ln x 1 * \ln x 5$ & $-0.190 * *$ & 0.081 & $0.001 *$ & 0.016 & 0.001 & 0.007 & -0.370 & 0.019 \\
\hline Land*feed & $\ln x 1 * \ln x 6$ & $0.123 *$ & 0.064 & $0.027 * *$ & 0.012 & -0.067 & 0.005 & 0.026 & 0.012 \\
\hline Lab*livestock & $\ln x 2 * \ln x 3$ & -0.338 & 0.044 & 0.003 & 0.028 & 0.784 & 0.018 & $-0.047 * *$ & 0.022 \\
\hline Lab*tractor & $\ln x 2 * \ln x 4$ & -0.017 & 0.012 & $-0.026^{*}$ & 0.016 & 0.117 & 0.003 & 0.026 & 0.019 \\
\hline Lab*fertilizer & $\ln \times 2 * \ln x 5$ & 0.601 & 0.008 & -0.007 & 0.006 & 0.012 & 0.010 & $-0.044 * *$ & 0.013 \\
\hline $\mathrm{Lab}^{*}$ feed & $\ln x 2 * \ln x 6$ & -0.022 & 0.047 & -0.048 & 0.006 & -0.003 & 0.006 & 0.012 & 0.001 \\
\hline Livestock*tractor & $\mathrm{r} \ln \times 3 * \ln x 4$ & -0.049 & 0.041 & -0.042 & 0.003 & 0.058 & 0.005 & $-0.016^{* *}$ & 0.004 \\
\hline Livestock*fert. & $\ln x 3 * \ln x 5$ & $0.015 * *$ & 0.006 & 0.031 & 0.032 & 0.015 & 0.008 & $-0.083 * *$ & 0.096 \\
\hline Livestock*feed & $\ln x 3 * \ln x 6$ & $-0.214^{*}$ & 0.011 & 0.012 & 0.014 & -0.036 & 0.012 & $-0.190^{*}$ & 0.008 \\
\hline Tractor*fert. & $\ln x 4 * \ln x 5$ & 0.053 & 0.004 & $0.037 * *$ & 0.016 & 0.057 & 0.002 & -0.910 & 0.001 \\
\hline Tractor*feed & $\ln x 4 * \ln x 6$ & 0.048 & 0.023 & -0.001 & 0.000 & 0.092 & 0.007 & $0.414 * * *$ & 0.004 \\
\hline Fertilizer*feed & $\ln x 5^{*} \ln x 6$ & 0.024 & 0.008 & $-0.034 * * *$ & 0.001 & $0.002 * * *$ & 0.006 & $0.022 * * *$ & 0.014 \\
\hline sigma squared & $\sigma^{2}$ & $0.078 * * *$ & 0.082 & $0.002 * * *$ & 0.004 & $0.148 * * *$ & 0.002 & $0.090 * * *$ & 0.001 \\
\hline gamma & $\mathrm{y}$ & $0.967 * * *$ & 0.002 & $0.785 * * *$ & 0.125 & $0.891 * * *$ & 0.001 & $0.842 * * *$ & 0.013 \\
\hline log likelihood & & 146.236 & & 123.149 & & 129.935 & & 141.058 & \\
\hline LR test & & 16.357 & & 49.921 & & 14.141 & & 88.725 & \\
\hline
\end{tabular}

Source: Computed from FAOSTAT Data (1961-2014) * significant at 10\%, ** significant at 5\%, *** significant at $1 \%$ 
Furthermore, the result on the pooled data revealed that all the variable inputs except fertilizer had a positive influence on agricultural output. The negative influence of fertilizer implies lack of accessibility, availability and high costs of chemical/inorganic fertilizer in Africa.

Table 3 demonstrates that agricultural production in Nigeria, Ghana and Cameroon exhibit increasing returns to scale of $1.723,1.195$ and 1.186 indicating that a percentage increase in all inputs will result in a $1.72 \%, 1.20 \%$, and $1.19 \%$ increase in the level of output. This implies that these countries are in stage one of the production process where increase in the level of all inputs used in production results in a more than the proportionate increase in output. This is an indication that there is more room for the countries to expand their scale to increase production in the long run, subject to good quality input usage. Benin agricultural production, on the contrary, exhibits a decreasing return to scale of 0.802 , which implies that a $1 \%$ increase in all inputs used in production will result to a less than proportionate increase in output

Table 3: Production Elasticities and Return to Scale in the Study Area

\begin{tabular}{llllll}
\hline Variable & Nigeria & Benin & Ghana & Cameroon & Pooled \\
\hline Land & 1.645 & -0.431 & -3.702 & 2.813 & 2.070 \\
Labour & -0.215 & -0.450 & 1.948 & -0.321 & 1.030 \\
Livestock & 0.649 & 0.246 & 3.634 & 0.040 & 0.151 \\
Tractor & -0.515 & 0.504 & -0.295 & -2.327 & 0.060 \\
Fertilizer & 0.064 & 0.835 & -0.328 & 0.879 & -2.046 \\
Feed & 0.095 & 0.908 & -0.062 & 0.102 & 0.234 \\
RTS & 1.723 & 0.802 & 1.195 & 1.186 & 1.699 \\
\hline
\end{tabular}

The Stochastic Frontier and Meta-Frontier Estimates for Agricultural Production in the Study Area.

An LR test to examine the null hypothesis that the four countries share the same technology was performed. If the four countries share the same production frontier (i.e., no significant difference between the single region frontiers), then there would be no reason for estimating the pooled MF production model. The analysis showed that the value of the LR statistic is 137.562 which is highly significant and implies that the null hypothesis is rejected. The result suggests that the four national stochastic frontiers for agricultural production in Africa are not the same, implying that production structure and technology adoption are different among the four countries. Hence, the meta-frontier technique is the appropriate estimation approach for this study and that any efficiency comparison among these countries should be undertaken with respect to the meta-frontier instead of the pooled stochastic frontier. Similar results have been obtained by Battese et al., (2004); Binam et al., (2008); Mariano et al., (2010); Moreira and Bravo-Ureta (2010) among others.

Table 4 shows the estimates for the pooled sample TL model and the linear programming estimates for the MF. The result revealed that land, livestock, tractor and feed increase agricultural production under both models (SFA and MF), while agricultural production is reduced by fertilizer in the SFA model.

\section{Technical efficiency and technology gap ratio}

The values of the TGR, together with the TE measures for the SPF and with respect to the MF are summarized in Table 5. The TGR values represent the distance between the meta frontier and the national efficiency frontier for a given vector of inputs A higher (lower) TGR value implies a smaller (larger) technology gap between the individual frontier and the MF. A TGR value of $100 \%$ is equivalent to a point where a regional frontier coincides with the MF.

The study reveals that the mean technical efficiencies from the stochastic frontier models are estimated to be $0.895,0.754,0.804$ and 0.763 for Nigeria, Benin, Ghana and Cameroon respectively. This implies that agricultural production in Nigeria, Benin, Ghana and Cameroon are 10.5\%, 24.6\%, $19.6 \%$ and $23.7 \%$ below their group frontier. Technical efficiency scores from the pooled data ranges from 0.822 to 0.986 with a weighted average of about $85 \%$, indicating that agricultural production in Africa produces 85 percent of the potential output given the technology available in each country. This result demonstrates that improving the managerial skills and technical capacity of farmers without adding any input can help increase agricultural output by up to 15 percent. Nigeria is relatively the most technically efficient country while Benin is the least efficient. Weather conditions, 
pest and diseases, imperfect competition, financial constraints, lack of improved crop varieties, etc., may cause a farmer not to be operating at optimal level (Nkamleu et al., 2010; Onumah et al., 2013).

Table 4: MLE Estimates of the SFA and Meta Frontier

\begin{tabular}{|c|c|c|c|c|c|}
\hline & \multicolumn{2}{|c|}{ Pooled SFA } & \multicolumn{3}{|c|}{ Meta Frntier } \\
\hline & Coef. & S.E. & Coef. & S.E. & \\
\hline Constant & $04.628 * *$ & 1.295 & $365.64 * * *$ & 23.249 & \\
\hline Inx 1 & $2.070 * * *$ & 0.316 & $7.092 * *$ & 3.011 & \\
\hline $\ln x 2$ & $1.037 * * *$ & 0.124 & -0.227 & 0.687 & - \\
\hline $\ln x 3$ & $0.151^{* * *}$ & 0.044 & $0.925 * * *$ & 0.246 & \\
\hline $\ln x 4$ & $0.060 * * *$ & 0.011 & $1.342 * * *$ & 0.223 & \\
\hline $\ln x 5$ & $-2.046^{*}$ & 0.026 & $2.270 * * *$ & 0.271 & \\
\hline $\ln x 6$ & $0.234 * * *$ & 0.016 & $0.324 * * *$ & 0.071 & \\
\hline$(\ln x 1) 2$ & $-0.101 * * *$ & 0.017 & $-0.542 * * *$ & 0.173 & \\
\hline$(\ln x 2) 2$ & $-0.045^{* * *}$ & 0.006 & $-0.116^{* *}$ & 0.047 & \\
\hline$(\ln x 3) 2$ & $-0.017 * * *$ & 0.003 & $-0.053 *$ & 0.031 & \\
\hline$(\ln x 4) 2$ & -0.153 & 0.001 & $-0.282 * * *$ & 0.030 & \\
\hline$(\ln x 5) 2$ & 0.014 & 0.002 & $-0.154 * * *$ & 0.021 & \\
\hline$(\ln x 6) 2$ & $0.003 *$ & 0.0015 & $0.016 * * *$ & 0.004 & \\
\hline $\ln x 1 * \ln x 2$ & $-0.024 * * *$ & 0.005 & $0.124 * * *$ & 0.028 & \\
\hline $\ln x 1 * \ln x 3$ & $0.013 * * *$ & 0.002 & $0.088 * * *$ & 0.026 & \\
\hline $\ln x 1 * \ln x 4$ & $-0.016 * * *$ & 0.006 & $0.021 * *$ & 0.011 & \\
\hline $\ln x 1 * \ln x 5$ & $-0.001 * *$ & 0.005 & $-0.002 * *$ & 0.011 & \\
\hline $\ln x 1 * \ln x 6$ & $-0.003 * * *$ & 0.008 & $0.065 * * *$ & 0.007 & \\
\hline $\ln x 2 * \ln x 3$ & $-0.052 * *$ & 0.002 & $0.015^{*}$ & 0.009 & \\
\hline $\ln x 2 * \ln x 4$ & -0.003 & 0.006 & $0.044 * * *$ & 0.001 & \\
\hline $\ln \times 2 * \ln x 5$ & $0.003 * *$ & 0.001 & $-0.061 * * *$ & 0.009 & \\
\hline $\ln \times 2 * \ln x 6$ & $0.001 * *$ & 0.005 & $-0.016^{* * *}$ & 0.009 & \\
\hline $\ln x 3 * \ln x 4$ & -0.003 & 0.004 & 0.524 & 0.007 & \\
\hline $\ln \times 3 * \ln x 5$ & $-0.002 * * *$ & 0.007 & -0.012 & 0.008 & \\
\hline $\ln x 3 * \ln x 6$ & 0.023 & 0.004 & $-0.118 * * *$ & 0.021 & \\
\hline $\ln x 4 * \ln x 5$ & -0.056 & 0.004 & -0.005 & 0.007 & \\
\hline $\ln x 4 * \ln x 6$ & $-0.021 * * *$ & 0.006 & 0.005 & 0.008 & \\
\hline $\ln x 5 * \ln x 6$ & $0.029 *$ & 0.001 & -0.007 & 0.006 & \\
\hline sigma squared & $0.005 * * *$ & 0.002 & & & \\
\hline gamma & $0.685^{* * *}$ & 0.236 & & & \\
\hline log likelihood & 322.896 & & & & \\
\hline LR test & 137.562 & & & & \\
\hline
\end{tabular}

Source: Computed from FAOSTAT Data (1961-2014) * significant at 10\%, ** significant at 5\%, *** significant at $1 \%$

Estimates of the technology gap ratios (TGR) reveal that the four countries have a mean potential ratio of $0.770,0.640,0.870$ and 0.680 in Nigeria, Benin, Ghana and Cameroon respectively. The values of the TGRs indicate that if agricultural producers in the four countries were technically efficient, they could have increased the output by closing a gap of $23 \%, 36 \%, 13 \%$ and $32 \%$ respectively. Estimate of the pooled TGR ranges from 0.650 to 0.970 with a mean of 0.774 . This implies that, on the average, the selected Africa countries will have to close a gap of about $22.6 \%$ in order for them to be technically efficient. Benin has the lowest productivity potential ratio. This suggests that even if all agricultural producers from Benin achieved best practice with respect to the technology observed in their country, they will still be lagging behind because the technology in Benin lags behind regional technology with a TGR of 0.640. This implies that even if the mean agricultural producer in Benin were fully technically efficient (i.e., producing on the national efficiency frontier), he/she would still need to increase output by 36 percent if he/she adopted the most efficient meta-technology in the region. Nkamleu et al., (2010) obtained a similar result for Cameroon in their study on technology gap and efficiency in cocoa production. 
Table 5: Technical Efficiency Scores and Technology Gap Ratios (TGR)

\begin{tabular}{lcccc}
\hline & Min. & Max. & Mean & S.D. \\
Technology gap ratios & 0.650 & 0.928 & 0.770 & 0.014 \\
Nigeria & 0.691 & 0.799 & 0.640 & 0.024 \\
Benin & 0.706 & 0.958 & 0.870 & 0.016 \\
Ghana & 0.726 & 0.970 & 0.680 & 0.019 \\
Cameroon & 0.650 & 0.970 & 0.774 & 0.020 \\
Pooled & & & \\
Technical efficiency (SFA) & 0.822 & 0.986 & 0.895 & 0.032 \\
Nigeria & 0.899 & 0.984 & 0.754 & 0.021 \\
Benin & 0.841 & 0.981 & 0.804 & 0.025 \\
Ghana & 0.833 & 0.984 & 0.763 & 0.018 \\
Cameroon & 0.822 & 0.986 & 0.848 & 0.238 \\
Pooled & & & & \\
Technical efficiency (Meta frontier) & 0.711 & 0.962 & 0.875 & 0.082 \\
Nigeria & 0.504 & 0.991 & 0.528 & 0.024 \\
Benin & 0.682 & 0.983 & 0.705 & 0.021 \\
Ghana & 0.717 & 0.967 & 0.756 & 0.019 \\
Cameroon & 0.711 & 0.997 & 0.783 & 0.014 \\
Pooled & & &
\end{tabular}

The technology gap ratios were greater in Ghana (0.870) than other countries, indicating that the technologies in Ghana are closer to the possibilities' frontier of the meta-technology than Nigeria, Benin and Cameroon. This further implies that if all factors are held constant, the producers in Ghana will reach the maximum potential output for agricultural production in West Africa faster than other countries.

The mean technical efficiency scores for the agricultural production in the selected countries relative to the meta-frontier are $0.875,0.528,0.705$ and 0.756 for Nigeria, Benin, Ghana and Cameroon respectively. This indicates that Nigeria is more technically efficient than other selected West Africa countries. An interesting point to note is the difference between the average technical efficiency scores from the national and the meta frontier models. For example, the average technical efficiency for Benin relative to the meta technology is 52.8 percent, while its mean efficiency is quite large with respect to its own national frontier $(75.4$ percent $)$. The differences between the two efficiency scores confirms the inappropriateness of the technical efficiencies obtained by using the SFA, relative to the technology available for agricultural production in West Africa.

\section{Conclusion and Recommendations}

This study applied meta frontier function technique to investigate technology gaps and technical efficiency in agricultural production in four Africa countries using secondary data sourced from FAOSTAT for a period of 54 years (1961-2014). The methodology enables the estimation of national technology gap ratios by using a decomposition result involving both the national production frontiers and the (regional) meta production frontier.

Separate stochastic frontier models were estimated for these countries, along with a stochastic meta production frontier to obtain alternative estimates for their technical efficiencies. The results of the analysis showed the technical efficiency scores from the region ranges from 0.822 to 0.986 with a weighted average of about $85 \%$, indicating that the agricultural production in Africa produces 85 percent of the potential output given the technology available in each country. The result also revealed large productivity potential gaps (TGR) between countries of the region in relation to agricultural production. The gaps range between 0.650 and 0.970 . These values can be interpreted as the technological gap faced by the agriculture sector in those countries when their performances are compared with the regional level. Benin recorded the lowest technology gap, while Ghana had the highest. In terms of technical efficiency relative to the meta frontier, Nigeria is the most technical efficient country while Benin appears as the least performing region.

The study makes it possible to identify the type of interventions each country needs to enhance her agricultural production. The fact that these countries are not realising the full potential of the system indicates that there is need for sustainable improvements in performance. 
The study therefore recommends that:

In Benin, the intervention should be to raise technology (to close the gap between the regional frontier curve and the global frontier curve). The improvement of efficiency is likely to require additional investment in research to adapt and develop new technologies.

Cameroon farmers will also require maximisation of their potentials to utilise available local technologies for maximum output. A promising possibility may be to train farmers (using extension officers, for example) in production programmes so that they gain more knowledge of crop and livestock management in addition to utilising new and adaptable technology.

Ghana and Nigeria could improve their performance through a better management using the available technologies and resources. Some of the management issues include applying the right quantity of fertilizers and agrochemicals, use of labour and machineries, etc. The level of technology in the countries is quite good, but the extent of their exploitation is not impressive.

\section{References}

Battese, G.E., and G.S. Corra, 1977. Estimation of a Production Function Model with Application to the Pastoral Zone of Eastern Australia. Australian Journal of Agricultural Economics, 21:169179.

Battese, G. E. and D. S. P. Rao, 2002. Technology gap, efficiency, and a stochastic metafrontier function. International Journal of Business and Economics, 1(2):87-93.

Battese, G. E., D. S. P. Rao, and C. O’Donnell, 2004. A meta frontier production function for estimation of technical efficiencies and technology gaps for firms operating under different technologies. Journal of Productivity Analysis, 21(1):91-103.

Binam, J.N., J. Gockowski, and G.B. Nkamleu, 2008. Technical efficiency and productivity potential of cocoa farmers in West Africa countries. The Developing Economics, 3: 242-263.

Blanke, J., 2017. Realising West Africa's true agricultural potential. Africa Development Bank. https://www.scibd.com/document/afdb-2017

Boshrabadi, H., R. Villano, and E. Fleming, 2008. Technical efficiency and environmental technological gaps in wheat production in Kerman province of Iran. Agricultural Economics, 38(1):67-76.

Bravo-Ureta, B.E., and A.E. Pinheiro, 1997. Technical, Economic and Allocative Efficiency in Peasant Farming: Evidence from the Dominican Republic. The Developing Economies 35(1), 48-67.

Chebill, A., A. H. Abdelaziz, O. H. Alawia,A. Ishtiag, T. Izzat,A. Solomon, and Y. Ouambi, 2016. Metafrontier Analysis of Technical Efficiency of Wheat Farms in Sudan. Journal of Agricultural Science, 8 (2): 179-186

Chen, Z., and S. Song, 2008. Efficiency and technology gap in China's agriculture: A regional metafrontier analysis. China Economic Review, 19(2):287-296

Coelli, T., D. S. P. Rao, G. E. Battese, 2005. An Introduction to Efficiency and Productivity Analysis, second edition, Kluwer Academic Publishers, Boston.

Greene, W. H., 2003. Econometric Analysis, fifth edition, ISBN: 0-13-110849-2, Prentice Hall, New York

Hayami, Y., 1969. Sources of Agricultural Productivity Gap Among Selected Countries. American Journal of Agricultural Economics, 51 (3), 564-575.

Hayami, Y. and V. W. Ruttan, 1970. Agricultural Productivity Differences among Countries. American Economic Review, 60 (5): 895-911.

Hayami, Y., V.W. Ruttan, 1971. Agricultural Development: International Perspective. Baltimore: John Hopkins University Press.

Henningsen, A., F. M. Daniel, S. A. Anwar, A. K. Joseph, and G. C. Tomasz, 2015. A Meta-Frontier Approach for Causal Inference in Productivity Analysis: The Effect of Contract Farming on Sunflower Productivity in Tanzania. Selected Paper prepared for presentation at the 2015 Agricultural \& Applied Economics Association and Western Agricultural Economics Association Annual Meeting, San Francisco, CA, July 26-28. 
Kontolaimou, A., and K. Tsekouras, 2010. Are cooperatives the weakest link in European banking? A nonparametric metafrontier approach. Journal of Banking \& Finance, 34: 1946-1957.

McMillan, M., and W. Chan, 2004. University efficiency: a comparison and consolidation of results from stochastic and non-stochastic methods. University of Alberta Economics Working Paper Series: No. 2005- 04.

Moreira V.H., B.E. Bravo-Ureta, 2010. Technical efficiency and metatechnology ratios for dairy farms in three southern cone countries: a stochastic metafrontier model. Journal of Productivity Analysis, 33: 33-45.

Mundlak, Y., and H. René, 1982. The Intercountry Agricultural Production Function: Another View. American Journal of Agricultural Economics 64, no. 4: 664- 72.

Nkamleu, G.B., J. Nyameck, and J. Gockowski, 2010. Technology Gap and Efficiency in Cocoa Production in West and Central Africa: Implication for Cocoa Sector Development. Working Papers Series No. 104, Africa Development Bank, Tunis, Tunisia.

Nyemeck, B.J., J. Gockowski,and G.B. Nkamleu, 2008. Technical Efficiency and Productivity Potential of Cocoa Farmers in West African Countries: A Meta Frontier Approach. The Developing Economies, 46(3): 242-63.

O'Donnell, C.J., D.S.P. Rao, and G.E. Battese, 2008. Metafrontier frameworks for the study of firmlevel efficiencies and technology ratios. Empirical Economics, 34(2): 231-255

Onumah, J.A., E.E. Onumah, R.M. Al-Hassan, and B. Brumme, 2013. Meta-frontier analysis of organic and conventional cocoa production in Ghana. AGRIC. ECON. CZECH, 59(6): 271280.

Otieno, D.J., L. Hubbard, and E. Ruto, 2014. Assessment of technical efficiency and its determinants in beef cattle production in Kenya. Journal of Development and Agricultural Economics, 6(6): 267-278.

Villano, R., H. M. Boshrabadi, and E. Fleming, 2010. When is meta frontier analysis appropriate? An example of varietal differences in Pistachio production in Iran. Journal of Agricultural Science and Technology, 12(4):379-389. 